\title{
Narrative view of the role of health promotion and salutogenesis in the treatment of chronic disease: viability and value for the care of cardiovascular conditions
}

\author{
Christina Röhrich $^{1} \wedge$, James Giordano ${ }^{2}$, Nikola Boris Kohls ${ }^{1}$ \\ ${ }^{1}$ Division Health Promotion, University of Applied Sciences and Arts, Coburg, Coburg, Germany; ${ }^{2}$ Departments of Neurology and Biochemistry, \\ and Pellegrino Center for Clinical Bioethics, Georgetown University Medical Center, Washington, DC, USA \\ Contributions: (I) Conception and design: C Röhrich; (II) Administrative support: None; (III) Provision of study materials or patients: None; (IV) \\ Collection and assembly of data: None; (V) Data analysis and interpretation: None; (VI) Manuscript writing: All authors; (VII) Final approval of \\ manuscript: All authors. \\ Correspondence to: Christina Röhrich, MSc. Division Health Promotion, University of Applied Sciences and Arts, Friedrich-Streib-Str. 2, 96450 \\ Coburg, Germany. Email: christina.roehrich@hs-coburg.de.
}

\begin{abstract}
Health promotion provides a complementary scientific and practical approach to medicine, which may help to create, maintain and restore wellness even in the presence of disease and illness. Salutogenesis, as key concept, focuses upon the emergence of health and thus, leads to fortifying individuals' and communities' health determinants and resources. The potential integration of health promotion and medicine can contribute to a more person-centred focus of integrative care to address and realize individuals' health potential and needs, rather than merely an emphasis upon the underlying disease, such as congenital heart diseases. We posit that it is possible - and advisable - to address lifestyle modification aspects, and to change the focus of therapeutic encounters and health care programs to be more tailored to and aligned with individual needs, demands and expectations. By adopting a health promotional approach to the individual patient as person, their subjective biography, narrative and lifeworld can serve as resources for developing more beneficial coping styles, resilience and trajectories for personal growth over the life span, despite the occurrence and durability of chronic conditions, such as long-term cardiovascular disease. Implications, important contingencies and requirements for education and training of health-care professionals are addressed, as they are key issues that may affect the successful development and engagement of health promotion programs within health care systems at-large.
\end{abstract}

Keywords: Health promotion; prevention; person-centred health care; person-centred medicine; chronic disease

Submitted Jul 06, 2020. Accepted for publication Nov 25, 2020.

doi: $10.21037 / \mathrm{cdt}-20-610$

View this article at: http://dx.doi.org/10.21037/cdt-20-610

\section{Limitations of medicine regarding the treatment of chronic diseases}

The number of individuals with chronic diseases is steadily increasing. The type(s) of disease prevalent in the majority of Western countries is also changing in recent decades. While it is notable and fortunate that infectious diseases are declining, chronic diseases such as diabetes and cardiovascular diseases, which in many cases are related to, or at least can be influenced by lifestyle and life circumstances, are increasing significantly (1).

At the same time, there is an increasing scope and use of technology in medicine. To a great extent, this has enabled patients with congenital heart defects (CHD), for example,

\footnotetext{
^ ORCID: 0000-0002-1996-3582.
} 
to increase both their life expectancy and quality of life (2). These new technological advances have also enabled an improved understanding of disease. In the main, research has addressed the genetic, biochemical, and physiological bases and correlates of pathology. This nosological approach has a long tradition in medical practice, beginning with Sydenham, and advancing through the use of ever more capable investigative tools through the 19th and 20th centuries (3). To be sure, the 'teaching hospital' and 'military hospital medicine' models are exemplary products ofand contributory to-this mechanistic approach to disease, injury, and treatment (4).

Yet, despite the successes of the acute care (i.e., more curative) model, there are numerous health conditions for which cure is not possible, yet that require relief (palliation) and recovery (rehabilitation) as well as amelioration. If we regard the patient in the literal sense, from the Latin etymology 'the one who suffers', those with such conditions are no less viable - and arguably may be more in needas the district focus of care. In such cases, care does not constitute cure, and thus a medical paradigm (of both clinical intervention and research) that is distinct from an acute care approach is required.

Indeed, Reiser has stated that (particularly as regards the patient with chronic conditions), “...medicine begins where technology leaves off". In many ways, this speaks to the ethical foundations of medicine as a discipline and in practice. Pellegrino and Thomasma have defined the "act of medicine: as the administration of a 'right and good healing" (5). What constitutes technical rectitudewhile surely the province of the clinician as steward of knowledge and skill-must be framed in and executed toward the primacy of the good of the patient. Pellegrino and Thomasma [1988] have also noted that such 'good' is four-fold: most proximate to the perspective of the clinician is the biomedical good. However, articulation of the acts of medicine must recognize, respect, and be responsible to the good of the patient's choices, and respect for the patient as a person. This concept of patient-as-person is critical to discerning those practices that are aimed at merely addressing the process of a disease versus those that are oriented toward reconstituting some sense of 'wholeness' in the afflicted person's agency and sense of identity. It is in this light that Fulford (6), and Waters and Sierpina (7) advocate the use of heterogeneous approaches that engage the biological, psychological, and social dimensions and domains that are often reflected in patients' values, goals, and life worlds. Indeed, it is what Engel (8) has described as the 'bio-psycho-social reality' of the physically-embodied and socially-embedded person that is often affected and fragmented by the burden of chronic conditions (9). This bio-psycho-social perspective has been advocated by the ICF-model (10).

\section{Patients with congenital heart disease are challenged to maintain, restore and create health}

Axiomatically, chronic conditions are durable and often persist for years, if not the whole lifespan, e.g., CHD. Chronic conditions can evoke changes in physiology that can render patients more susceptible to other, more acute, concomitant diseases (2). In addition, changes that occur as a result of aging processes can aggravate pre-existing conditions; recent shifts in social demographics have made these conditions more prevalent, evident, and the focus of a growing body of research (11). Any profound change as a consequence of increased life span has the potential to concomitantly increase the risk of chronic conditions, such as CHD, and the physiological and psychosocial challenges they can incur (12-15). Interdependencies of biological, psychological and social domains and effects increase the complexity of patients' health and can thereby influence their overall wellbeing and quality of life. Those affected by chronic heart conditions must adapt to a life that is preserved by - and burdened with ongoing medical encounters, invasive procedures, and the relative uncertainties and fears that iterative change in health status and physical capability evoke $(15,16)$. Gadamer $(17)$ has discussed the relative-and rather tenuous-security that lies behind the "concealment of health". Gadamer notes that the perceived integrity of persons' lived body and life world are often sharply contrasted - and disrupted-by the onset and progression of disease, and the phenomenological burdens and changes it renders.

Pellegrino (18) saw medicine as "...the most humanistic of the sciences, and the most scientific of the humanities". Thus, if medicine is to remain apace with a technologicallyenabled understanding of disease, as well as current insights to (subjective) illness, and humanistic views of the patient-as-person that is the subject of the practice's moral regard, there is ethical obligation to explore, develop, and adopt clinical practices that more genuinely and nonwastefully provide both individual good to the patient, and public good to society (19). This requires innovative and complementary approaches in practice and research that go 
beyond a simple understanding of disease (however complex such understandings may be), to explore and address those conditions and mechanisms through which health can be created, maintained, fortified and restored. We contend that it is not a circumstance of 'either (curative)/or (healing)', but rather a continuum and reciprocally complementary enterprise of using 'both/and' each, as required, and of maximal benefit to the patient-as-person. Without doubt, the burden of disease impacts the crucial dimensions of psychological functioning, and thus an intrinsic goal of any bio-psycho-socially-relevant approach is to deal with (and turn) psychological challenges as venues for possibilities of personal growth, transformation and development. To be sure, we will all be patients, at some point in our lifetime. A person's vulnerability to chronic disease can increase over the course of an extended lifetime as consequence of lifestyle choices and activities, and socio-economic situation, environmental influences and the onset and development of chronic disease often increases the vulnerability to, and likelihood of contracting other conditions. In this way, patients with congenital heart diseases are particularly at risk for acquiring additional vulnerabilities (20).

But rather than proposing new technological solutions, herein we offer a different perspective of therapeutic and interventional thinking and acting that allows development of a complementary, health promotional approach to deal with the challenges of chronic conditions, in general, and chronic cardiovascular disease, more specifically. A promising orientation is the integration of medicine, psychology, social care, and health promotion (21). We posit that synergy of these fields (in research and applied clinical practice) can improve prevention, treatment, and resiliency by affording lifestyle-relevant methods for dealing with chronic diseases and their (bio-psychosocial) effects. Prerequisite for this approach is a coherent orientation to the person who is the patient, their individual lifeworld, values and goals, and subjective narrative (22).

\section{Prevention is still relevant even for already existing diseases}

The general aim of prevention (of any sort) is to avert the onset and progression of disease by reducing risk factors $(23,24)$. Primary prevention aims to address and foil the sources and development of disease, while secondary prevention focuses on early detection and the inhibiting the onset of disease if and when risk factors are present and/or inexorable. Tertiary prevention entails activities to prevent the progression of disease, and occurrence of additional secondary risk factors. For example, preventing psychological comorbidity in children and adults with congenital heart defects is of utmost clinical health promotional value because of the enhanced vulnerability that results from reoccurring life-threatening conditions and medical procedures (20).

In Germany, the Prevention Act (PrävG) of 2015 aims to anchor and strengthen health promotion and prevention within state-operated structures and the health care system. Health care insurance companies provide an annual investment volume of approximately 500 million Euros for this purpose. The goal is to create suitable prevention and health promotion strategies and services that are viable for people to employ in their living environments (e.g., at home, at work, in school, but note that for many patients suffering from chronic health conditions a clinical content may be considered a "natural habitat"). In addition, the statutory health insurance funds subsidise a variety of prevention courses via the Central Prevention Evaluation Centre (ZPP) in exercise, nutrition, stress management and prevention of drug use/abuse.

\section{Health promotion as a complementary approach to medicine}

The boundaries of health promotion and prevention are somewhat 'fuzzy', and these terms are frequently conflated in both use and meaning. Prevention is a rather wellestablished and integrated component of many developed health-care systems, possibly because the general conceptual framework is concordant with the biomedical approach that is focused on diagnoses, oriented towards aetiology, and addresses risk-factors of disease. In contrast, health promotion does not aim to reduce risk factors, per se, but rather attempts to identify and fortify determinants and resources of health (i.e., 'protective factors') and in this way, leads to a different conceptual approach, which is considerably more comprehensive than prevention alone.

In this light, health promotion refers to the complex individual, social and political process(es) that are committed to facilitate healthy lifestyles of individuals and groups by improving conditions of the social and systemic framework relevant for wellness and quality of life as well as human flourishing. According to the World Health Organization (25), health promotion is best understood (in terms of Western Enlightenment, and phenomenological philosophy) as a process by which a person gains greater 
control over their own health and thereby understands and better engages means to incur positive influence in their lifestyle, lifeworld, and lived body.

\section{Salutogenesis, or: how does health emerge?}

Axiomatically, health promotion focuses on the determinants and factors that evoke, support and sustain health. The technical term originating from Latin for this is salutogenesis: salus $=$ health, genesis $=$ emergence $(26)$. Studies of salutogenesis are dedicated to investigating and elucidating the development of health, and thus consider processes and influencing factors that promote and maintain health. Health and illness are considered not as differing entities, but as opposite poles of a spectrum or continuum. Therefore, illness and health are perceived as co-existing conditions rather than being regarded-and treated-as mutually exclusive. A person's state of health and illness moves along this spectral continuum of expression and effect throughout the entirety of the life span. Salutogenesis therefore conceptualizes disease as relative to health. Such a relational understanding of disease is difficult to position within the more static, regnant biomedical system of disease classification, which requires objective parameters (of mechano-physical dysfunctionality), and tends to neglect subjective (i.e., first-person experiential, phenomenologically expressed and encountered) dimensions of illness. Salutogenesis recognizes aspects of health within a person regardless of the state and extent of disease. This is not contrary to medicine as classically conceived, but instead complements and thus functionally balances the medical understanding of risk-factors with health protection factors as counterpart.

With regard to health protection factors, health promoting interventions are aimed at micro (i.e., individual genetics, gender, lifestyle), meso (i.e., community, social networks, work-life, lifeworld) and macro (i.e., socioeconomical, political, environmental) levels (27). Health protection factors are important for the extent to which a person experiences life as a meaningful, understandable, and manageable process-particularly in/during difficult life situations inclusive of those arising in/from disease and subjective illness. The presence of meaningfulness, comprehensibility and manageability create a sense of coherence. The stronger the sense of coherence, the easier it is for persons to master life in self-determined and selfresponsible ways, and to develop iterative possibilities for promoting health even in the presence of illness (28). In this way, facilitating a sense of coherence can lead to an upward spiral of well-being and wellness, often despite objectively compromised biological functionality (that are typically viewed in medicine as constructs of poor health $(29,30)$.

\section{Sense of coherence as health promoting factor in the presence of disease and illness}

Antonovsky's studies of female survivors of Nazi concentration camps revealed that $29 \%$ of women managed to survive the horrors of the camps without any apparent psychological insult. Antonovsky posited that such capability was due to a psychological phenomenon he initially dubbed 'hardiness'. Further research led him to revise the hardiness concept to encompass a broader construct - the aforementioned sense of coherence-which is the ability to understand and anticipate life circumstances, experience life events as meaningful, and to have abilities to identify resources to overcome adverse life events (26). The existential importance of making meaning in attempts to overcome existential crises (viz., as logogenesis/ logotherapeutics) has been well described by psychiatrist (and concentration camp survivor) Frankl (31).

\section{Subjective narratives of patients are relevant}

In health care contexts, an exploration and promotion of factors underlying and contributing to a sense of coherence require engagement of more subjective theories ofand approaches to-health and illness. However, this poses certain demands upon the skills, knowledge and relationships of health care professionals and providers (e.g., communication skills, knowledge/experience to complement a pathogenetic perspective with a salutogenetic perspective; attitudes/skills of subjective narrative (32). In assuming this stance, health care professionals will need to shift their role in the clinical encounter from a paternalistic/parentalistic to a more egalitarian role in which partnership with the patient is combined with professional expertise (e.g., in developing and enacting a palette of shared decision-making skills and options as well as an attitude and technique for the ability turning towards the patients' subjective narrative). Prerequisite for the patient is to experience this sense of partnership with the health care professional; however crucial to this dynamic is the clinician's attitude of acceptance towards the patient's subjective narrative. The subjective narrative is a path that can guide the health care professional in establishing a more insightful relationship 
with the person who has been rendered to be the patient. To engage this approach the health care professional can seek orientation within the idiomatic language of the patient-the idiolect that comprises and explicates the foundations and perspectives of the patient's subjective reality in detail and with precision. This narrative provides insight to needs, values, goals, and constraints, and affords the clinician insight to (I) the particularity of the individual, (II) the assessment and offering of the 'good(s)' of care; (III) the resolution of clinical equipoise; (IV) the basis of informing the patient of treatment/care options available; and $(V)$ the probity of the patient's consent. In these ways, it instantiates the patient's autonomy, personal responsibility, and empowerment (22), and in this sense, health promotion regards persons as 'subjective experts of their lifeworld and lived body' and as principal executor of their health and well-being.

\section{Patient empowerment as prerequisite for developing coping styles}

Empowerment refers to efforts to enable and strengthen an individual with regard to the bio-psycho-social (inclusive of existential/spiritual and/or religious component) dimensions that are especially important to one's own well-being, quality of life, and to subjective perceptions of health and illness. In the context of illness, individuals often feel powerless against pain, physical changes, and medical assessments, treatments and judgements implicit or explicit to diagnoses and categorization as being 'sick' $(15,16)$. An important challenge for the patient with chronic illness is to emancipate oneself from the powerlessness, which often is experienced within medical encounters or through interaction(s) with the health care system, and to re-conquer one's own life thereby creating an attitude of an internalized locus of control leading to a heightened degree of selfefficacy. Patients with CHD often require intensive medical care, sometimes from birth and onwards. How might individuals bearing this human predicament experience a (more) internalized locus of control, and in which way(s) can empowerment be facilitated to develop a sense and experience of well-being over the life span? We may view empowerment as a continuous and long-term, dynamic and interactive process, intended to achieve a higher degree of health self-determination. Lenz (33) describes empowerment as a "professional attitude [...], providing opportunities for the development of competencies, making situations manageable and thus initiate 'open processes".
Regardless of the nuances of definition, empowerment involves dimensions of power and influence as key objectives of health promotion. This is described within the Ottawa Charter's (34) three central strategies: (I) active advocacy for health and the influence of relevant factors (advocacy), (II) competence development and empowerment with the aim of realising health potential (enable) and (III) mediation and networking for the formation and consolidation of cooperation (mediate).

\section{Meaning-making, coping, resilience and personal growth emerging in contexts of disease and illness}

Empowerment should be understood as a process that cannot be easily objectively measured or operationalized. Similar, and related to the concept of empowerment is the concept of self-efficacy, which establishes that a person has belief and capability to hold the locus of control-and the competency to handle life-within herself/himself (35). Achieving self-efficacy can prevent further comorbidities, and may facilitate the development of helpful coping styles by encouraging the individual to make meaning from subjective narrative. Such narrative-and its interpretive value is relevant to perception, acceptance, and capacity to bear and mitigate the burden of suffering resulting from the complex dynamics of physical, psychological, existential, spiritual and social dimensions of the life world and lived body (36-38). Meaning-making ideally results in an integration of the existing subjective narrative. In its broadest sense, within a Piagetian approach, the process of integration follows a trajectory of learning that entails assimilation and accommodation. Both are central to the development of increasing competency for self-regulation, self-modulation, and coping. The terms 'assimilation' and 'accommodation' depict complementary adaptive processes, that are employed to create a psychophysiological state of equilibrium between a person and their environment (39). These processes aim to reduce perceived discrepancies between a 'real' and a 'desired', future oriented self. Assimilation obtains ability to adjust living conditions so that the construal of 'self' (i.e., the realistic re-appraisal of real and desired self) are consonant with personal standards and goals. The accommodative process enables a person to utilize coping strategies by adapting personal standards and goals in order to experience a coherent self, even though original goals and standards are no longer viable given extant imposed limitations. Generally, accommodative 
processes become relevant-and engaged-when assimilative efforts fail (39).

Like health protection factors, a sense of coherence (with underlying aspects of meaningfulness, comprehensibility, manageability or more functionally expressed self-efficacy) contribute to a person's resilience when enduring adverse events $(37,40)$. Resilience tends to be conceptualized as 'bouncing back', very much reflective of the early research of Antonovsky regarding 'hardiness'. In four decades of studying a Mauwai population, Werner (40) has identified protective factors that facilitate resilience in the sense of 'thriving despite adverse circumstances'. Calhoun and Tedeschi (37) studies of patients suffering from a variety of life-threatening medical conditions, found that individuals have the ability to 'bounce back' or 'thrive despite' difficult experiences, and also to grow beyond their prior state(s) of psychological well-being. Their research focused on post-traumatic growth, which they contrast to posttraumatic stress syndromes. Differing from previous conceptualizations of resilience, post-traumatic growth implies a transformational change of the individual in a direction of 'greater health' as a process of maturation in the presence of suffering [as was suggested within the logotherapeutic approach of Frankl (31)]. A health promoting perspective would advocate the concept of post-traumatic growth and transformation as particularly important to patients with CHD, to serve as a model for reframing the subjective narrative of illness and to promote personal developmental processes over the life-span. This can lead to profound shifts in the experience of, and attitudes toward health and illness, with the possibility to encounter disease and illness as a question that life poses that requires deeper examination (via an internalized locus of control and action), rather than merely a problem that requires medical response and repair (and which is predicated upon, and instantiated from an externalized locus of control).

By perceiving long-term conditions like CHD as reoccurring or consistent trauma or crisis situations, we offer a more philosophical view, which positions the different facets of a crisis situation and the corresponding psychophysiological demands as aspects of phenomenological construction. The German word 'aufheben' ('lifting up') or 'aufgehoben' ('lifted up') have three meanings that are psychologically relevant for apprehension and management of crises. The terms describe a process that must necessarily be engaged in a certain sequential order if one wants to pass through and survive a crisis, and also to personally grow:

(I) In the first phase, 'aufgehoben' is understood as 'annulled', indicating that a subjective perception of normality is destabilized by an external or internal event in such a way that the integrity of the psychophysiological system is severely threatened. The previous state of normality is no longer there and a crisis has become apparent, e.g., by a certain diagnosis or a medical emergency or a psychosocial event such as a broken relationship or a loss of occupation.

(II) In the second step, 'aufheben' literally means to lift up, suggesting that the situation requires an individual response in the form of a psychophysiological adjustment, so that the anomaly is contained by means of psycho(physiolo) logical processes (such as adaptation or habituation). This is frequently achieved by means of self-transformation and it is therefore not surprising that this narrative is in many cases considered to be the core component of spiritual or religious experiences affecting the whole individual life trajectory (41).

(III) When a person has succeeded in the second step (i.e., realized transformation, and has thereby 'lifted' the anomaly, mostly through an inner process of change, which can often be accompanied by changed behaviour, values and attitudes), a third step enables salvaging the hidden potential that lies in the development process initiated by the crisis situation. The individual has now arrived at a new level of development, and has thus been 'lifted' in the sense of being saved and "harboured" thereby becoming 'another person' through the crisis. In this way the person has managed to integrate the crisis into their (new found) identity.

At this point, it becomes clear, of course, that these processes indicated have much to do with concepts such as mindfulness, meditation, and/or spirituality, and that so-called conversion experiences are, in fact, culturalanthropological constants that can be found in both religious and secular contexts throughout human history, civilizations and cultures. In recent years, evidence-based programmes to improve self-reflection and self-regulation have also been developed within mind body medicine and health promotion (as well as positive-psychology based) interventions. Such approaches have been shown to be effective and beneficial in dealing with crises. Given such 
findings, we opine that these considerations are highly relevant for health-related problems, and therefore we suggest and advocate functionally incorporating these methods in both health care approaches to chronic conditions, as well as in models of individual and community health promotions.

\section{Turning toward the person who is the patient}

To facilitate transformational changes, health promotion interventions should address the patient and, ideally, relevant others and involved institutions in specific ways. A health promoting approach implies the creation of therapeutic/ healing relationships and environments. Research has prompted translational advances in the relational basis of the clinical encounter, and have promoted the adoption of more person-centred practices in health care that address the 'individual person who is the patient' and furthermore the 'patient who is a person' $(32,42)$. While the role of being a patient may serve as a protective veil for a person to present the vulnerability of their humanity without feelings of shame or guilt, in the regnant medical culture, which is dominated by normative constructs and thinking, this formally protective role can merge into a mere façade of numbers and parameters. The technologically-based reality of modern medicine tends to reduce/minimize the more humane and individual aspects of the person-as-patient, in order to maintain objective precision. However, while certainly precise, this approach-although regarded as "personalized"often subjugates the "person" to the data-construct of the patient, leading to a distancing (or at least a superficiality) within patient-health care professional relationship. To reclaim and engage the humane aspect of patient-centred health care, we opine that health care professionals must learn methods of inter-subjectivity, which more fully obtain insight to the patient-qua-person, and concomitantly sustain capacity for objectivity [i.e., a discretionary space, that Osler referred to as "equanimity" (43)]. Although laudable, sustaining such change in clinical practice(s) will require a shift in health care professionals' mindset toward unconditional recognition of the validity and value of patients' subjective experience (in addition, and as complementary to appreciation of objective medical assessments and findings). Further, this shifting mindset may allow a re-appraisal and less circumspect presentation of the 'person who is the health care professional' (44).

Still, recognizing a person's subjective experience poses considerable challenge(s) in everyday medical practice
$(42,45)$. One of the obvious impediments is medicine's disciplinary and doctrinal reliance upon obtaining, deriving and making diagnostic, therapeutic, and prognostic decisions and conclusions from objective parameters and findings. It is important to applaud the extent to which this paradigm has facilitated a number of successful diagnostics and treatments. Yet, exclusive validity of objectivity inevitably biases perceptions against the validity and value of individuals' subjective narrative. To re-iterate, it is not a question of choosing one approach in favour of the other, but rather that the scientific paradigm requires the fortification provided by complementary qualitative research, findings and methods to enable health-care professionals to proactively employ both objective and subjective approaches to-and for-the patient (45).

To engage person-centred and/or subject-oriented health care, professionals should be provided tools that enable such a shift in their professional role, such as communication skills with orientation towards the idiolect, to encompass subjectivity within the individual and inter-individual use of language (46). This allows a turn toward the subjective experience and dimensions of suffering, and better depicts those services and resources that may be required for restoring health and/or a sense of well-being. Furthermore, the use of the patient's language (as idiolect) can facilitate bridging distancing that has occurred within the patientclinician relationship. Interestingly, we posit that such effect is not merely uni-directional, but may also enable the health care professional to be more humane (i.e., representative of their own sense of being a person) while engaging and executing the act(s) of profession. Such an approach may foster a renewed humanising of health care, and in this way, contribute to an integrative anthropology that can inform individual—and community—focal subject-orientation. We believe that this may of particular value when attempting to construct a more comprehensive depiction, analysis, and address of the complex issues that create the experience of patienthood in persons with long-term health conditions, such as CHD. These perspectives are axiomatic, and therefore somewhat intuitive for health promotion, and we propose that developing a shared and integrative approach to medical practice may allow appreciable gain(s) to be garnered in caring for individuals with long term, complex conditions.

Health promotion enables more effective and efficient engagement of coping resources and strategies. By utilizing these approaches, clinicians and patients can develop shared understanding of disease, subjective experience of illness, 
and the needs, goals and methods of care. Using these methods, the nature of dysfunction and the focus of care is not merely 'the heart', for example, or some other organ system, but rather, the whole person as a 'system of systems', embedded in systems of time, place and circumstance, consequentially a 'whole systems approach'. Consequentially, a whole-person-systems-based approach should serve as the pediment to address lifestyle issues, therapeutic plans and interventions, and the patient's role in understanding, addressing and improving their predicament of disease and its manifest illness and related sickness. Beyond theoretical and clinical merit, this orientation and approach may be seen as an ethical responsibility that is contingent upon modern medicine's capability and enterprise to extend the human lifespan, despite the presence and burden(s) of chronic disease (47). It is interesting to consider these points in light of the fact current therapeutic guidelines advocate the benefit of such complementary approaches in the care of several chronic conditions, inclusive of a number of cardiovascular disorders (47).

\section{Barriers to implementation of health promotion in the current healthcare system}

At present, many health care systems fail to implement strategies that encourage health promotional perspectives and methods. In part, this is because at this point it (still) seems more intuitive to address normatively and objectively oriented medical conditions with clinician-administered medicaments and procedures, rather engaging the patient in partnership toward the restoration and sustenance of their own subjectively encountered health parameters in. Often this is attributed to patients' reluctance to accept responsibility for decisions and behaviours that are focal to their health and wellbeing. To be sure, there are a number of reasons that could prevent change at both the individual patient and health systemic levels, including (I) health care paradigms that less than completely or validly acknowledge subjective experience and narrative; (II) medicine's tendency to both objectify disease and the person (as patient) in whom disease is expressed; (III) a paucity of financial incentives for health promotion programs; (IV) inadequate economic bases for creating and maintaining healing environments; (V) a lack of scientific research addressing longitudinal designs to evaluate and demonstrate the effectiveness of health promotion programs, and (VI) insufficient competencies of health-care professionals to provide salutogenetic health care. Given these factors, it is hardly surprising that health promotion has not yet been well-recognized as a relevant and important contribution to individual and community well-being, and health care systems writ-large.

\section{Toward an integration of medicine and health promotion}

In order to develop and more fully engage the potential of health promotion and salutogenesis in medicine, it will be necessary - and promising - to integrate these disciplines on scientific, clinical, social, and economic levels. The salutogenetic perspective, and methodological approach to subject-orientation/person-centeredness should be incorporated to the education and training curricula of (all) health care professionals and providers. Given the extant lack of medical humanities in the medical educational system prevalent at least in Central Europe, topics relevant to health promotion are predominantly taught within medical psychology, and usually at a rather early stage in the medical training process. In many ways, this fails to gain requisite attention, and equally fails to provide an iterative basis of health promotional knowledge and skills to the medical student throughout their educational development. However, any realistic hope-or intentto implement a more comprehensive approach to health promotions' education and training must acknowledge the necessity of sustainable financial programmatic support. Thus, a first step toward establishing health promotion on a practical and structural level within medicine can be achieved created through research that demonstrates the effectiveness and efficiency of salutogenetic approaches both in medical practice, and as a broadly disseminable public good, particularly in long lasting chronic conditions such as congenital heart diseases. Without doubt, the needs of patients (as recipients of care) as well as those of the medical community (as providers of care and patient benefactors) must be met by the outcomes and products of such research that has to stick to the rules of evidence-based medicine guidelines. Indeed, we perceive the need, and call for change in current models of conceptualizing and treating the patient-as-person. Our proposal for the integration of health promotions' models is neither naïve or uncritical. Change requires effort in education, economics, and the ecology of human health and the health care systems that are designed and created to support it. We remain focused upon and dedicated to these efforts and their realworld results in both medicine and society and opine that particularly congenital heart diseases might be an excellent 
area to bring our ideas and concepts into application.

\section{Acknowledgments}

Funding: None.

\section{Footnote}

Provenance and Peer Review: This article was commissioned by the Guest Editors (Yskert von Kodolitsch, Harald Kaemmerer, Koichiro Niwa) for the series "Current Management Aspects in Adult Congenital Heart Disease (ACHD): Part III" published in Cardiovascular Diagnosis and Therapy. The article has undergone external peer review.

Conflicts of Interest: All authors have completed the ICMJE uniform disclosure form (available at http:// dx.doi.org/10.21037/cdt-20-610). The series "Current Management Aspects in Adult Congenital Heart Disease (ACHD): Part III" was commissioned by the editorial office without any funding or sponsorship. The authors have no other conflicts of interest to declare.

Ethical Statement: The authors are accountable for all aspects of the work in ensuring that questions related to the accuracy or integrity of any part of the work are appropriately investigated and resolved.

Open Access Statement: This is an Open Access article distributed in accordance with the Creative Commons Attribution-NonCommercial-NoDerivs 4.0 International License (CC BY-NC-ND 4.0), which permits the noncommercial replication and distribution of the article with the strict proviso that no changes or edits are made and the original work is properly cited (including links to both the formal publication through the relevant DOI and the license). See: https://creativecommons.org/licenses/by-nc-nd/4.0/.

\section{References}

1. GBD 2017 DALYs and HALE Collaborators. Global, regional, and national disability-adjusted life-years (DALYs) for 359 diseases and injuries and healthy life expectancy (HALE) for 195 countries and territories, 1990-2017: a systematic analysis for the Global Burden of Disease Study 2017. Lancet 2018;392:1859-922.

2. Schwerzmann M, Thomet C, Moons P. editors. Congenital heart disease and adolescence. Cham: Springer
International Publishing, 2016.

3. Porter R. editor. The Cambridge History of Medicine. Cambridge: Cambridge University Press, 2006.

4. Ellis $\mathrm{H}$. The battle of Gettysburg: the dawn of the modern military hospital system. Br J Hosp Med (Lond) 2013;74:354.

5. Pellegrino ED, Thomasma DC. For the patient's good: the restoration of beneficence in health care. New York: Oxford University Press, 1988.

6. Fulford KW. Ten principles of values-based medicine. In: Radden J. editor. The philosophy of psychiatry: a companion. Oxford: Oxford University Press, 2004:205-34.

7. Waters D, Sierpina VS. Goal-Directed Health Care and the chronic pain patient: a new vision of the healing encounter. Pain Physician 2006;9:353-60.

8. Engel GL. The need for a new medical model: a challenge for biomedicine. Science 1977;196:129-36.

9. Giordano J, Kohls N. Spirituality, suffering, and the self. In: Giordano JJ. editor. Maldynia: multidisciplinary perspectives on the illness of chronic pain. Boca Raton: CRC Press, 2010.

10. World Health Organization. International Classification of Functioning Disability and Health (ICF). Geneva: World Health Organization, 2001. Available online: http://gbv. eblib.com/patron/FullRecord.aspx?p=763020

11. Schülke AM, Plischke H, Kohls NB. Ambient Assistive Technologies (AAT): socio-technology as a powerful tool for facing the inevitable sociodemographic challenges? Philos Ethics Humanit Med 2010;5:8.

12. Neidenbach R, Niwa K, Oto O, et al. Improving medical care and prevention in adults with congenital heart diseasereflections on a global problem-part I: development of congenital cardiology, epidemiology, clinical aspects, heart failure, cardiac arrhythmia. Cardiovasc Diagn Ther 2018;8:705-15.

13. Müller J, Berner A, Ewert P, et al. Reduced health-related quality of life in older patients with congenital heart disease: a cross sectional study in 2360 patients. Int J Cardiol 2014;175:358-62.

14. McMurray R, Kendall L, Parsons JM, et al. A life less ordinary: growing up and coping with congenital heart disease. Coronary Health Care 2001;5:51-7.

15. Kovacs AH, Utens EM. More than just the heart: transition and psychosocial issues in adult congenital heart disease. Cardiol Clin 2015;33:625-34, ix.

16. Meentken MG, van Beynum IM, Legerstee JS, et al. Medically related post-traumatic stress in children and adolescents with congenital heart defects. Front Pediatr 
2017;5:20.

17. Gadamer HG. Über die Verborgenheit der Gesundheit: Aufsätze und Vorträge. 1st ed. Berlin: Suhrkamp, 2010.

18. Pellegrino ED. Humanism and the physician. 2nd ed. Knoxville: The University of Tennessee Press, 1981.

19. May WF. Contending images of healer in an era of turnstile medicine. In: Walter JK, Klein EP. editors. The story of bioethics: from seminal works to contemporary explorations. Washington DC: Georgetown University Press, 2003:149-64.

20. Neidenbach R, Nagdyman N, Oberhoffer R, et al. Angeborene Herzfehler im Langzeitverlauf: Lebenslange Betreuung der Patienten. Pädiatrie 2017;29:28-33.

21. World Health Organization. Framework on integrated, people-centred health services. 2016 (cited 2020 Jun 29). Available online: https://apps.who.int/gb/ebwha/pdf_files/ WHA69/A69_39-en.pdf

22. Röhrich C, Krüger E, Kohls N. Gefühl und Vernunft als leibliches Erleben - Zur Relevanz von Subjektivität für ethische Bezüge im Kontext von Gesundheitsförderung. Internationale Zeitschrift für Philosophie und Psychosomatik 2018;(1):1-8.

23. Kisling LA, Das JM. editors. Prevention strategies. Treasure Island: StatPearls Publishing, 2019.

24. Definition der Präventionsmedizin. 2018 (cited 2018 Nov 26). Available online: https://www.dgnp.de/wir-ueber-uns/ definition-der-praeventionsmedizin.html

25. Die Jakarta Erklärung zur Gesundheitsförderung für das 21. Jahrhundert. 1997.

26. Antonovsky A. Unraveling the mystery of health: How people manage stress and stay well. 1st ed. San Francisco: Jossey-Bass, 1988.

27. Dahlgren G, Whitehead M. Policies and strategies to promote social equity in health. Background document to WHO - Strategy paper for Europe. Arbetsrapport 1991;2007:14.

28. Bengel J, Strittmatter R, Willmann H. Was erhält Menschen gesund?: Antonovskys Modell der Salutogenese - Diskussionsstand und Stellenwert; eine Expertise. Erw. Neuaufl. Köln: BZgA, 2009.

29. Bauer GF, Roy M, Bakibinga P, et al. Future directions for the concept of salutogenesis: a position article. Health Promot Int 2020;35:187-95.

30. Kohls N. Antonovskys Kohärenzgefühl - eine säkularisierte und psychologisierte Form von Spiritualität. In: Sigl C, Offenbächer M. editors. Salutogenese. Gesundheit trotz chronischer Krankheit - Was tun, wenn man nichts mehr tun kann? München: Pflaum, 2010:51-76.
31. Frankl VE. Ärztliche Seelsorge: Grundlagen der Logotherapie und Existenzanalyse: mit den Zehn Thesen über die Person. Ungekürzte Ausg. 12th ed. München: Dt. Taschenbuch-Verl.; 2007.

32. Santana MJ, Manalili K, Jolley RJ, et al. How to practice person-centred care: a conceptual framework. Health Expect 2018;21:429-40.

33. Lenz A. editor. Empowerment: Neue Perspektiven für psychosoziale Praxis und Organisation. Tübingen: dgvtVerl., 2002.

34. Ottawa Charter for Health Promotion: First International Conference on Health Promotion, Ottawa, Canada, 17-21 November 1986. 1986.

35. Bandura A. Self-efficacy: the exercise of control. 13th ed. New York: Freeman, 2012.

36. Park CL. The Meaning Making Model: A framework for understanding meaning, spirituality, and stressrelated growth in health psychology. European Health Psychologist 2013; 15.2:40-7. (cited 2020 Jun 29). Available online: https://pdfs.semanticscholar.org/8c66/c6 adff378f50aec1c8026694f4c4099c402f.pdf

37. Calhoun LG, Tedeschi RG, editors. Handbook of posttraumatic growth: research and practice. Repr. London: Routledge, 2009.

38. Li Z, Long TL. The meaning management challenge. Boston: BRILL, 2020.

39. Brandtstädter J. Positive Entwicklung: Zur Psychologie gelingender Lebensführung. Heidelberg: Springer Berlin Heidelberg, 2011. Available online: http://site.ebrary.com/ lib/alltitles/docDetail.action?docID=10490111

40. Werner EE, Smith RS. Journeys from childhood to midlife: risk, resilience and recovery. Ithaca: Cornell University Press, 2001.

41. Kohls NB. Außergewöhnliche Erfahrungen - blinder Fleck der Psychologie?: Eine Auseinandersetzung mit außergewöhnlichen Erfahrungen und ihrem Zusammenhang mit geistiger Gesundheit [Zugl.: Freiburg (Breisgau), Univ., Diss., 2004]. Münster: Lit; 2004.

42. van Dulmen AM, McCormack B, Eide H, et al. editors. Person-centred healthcare research. Hoboken: John Wiley \& Sons Ltd., 2017. Available online: http://onlinelibrary. wiley.com/book/10.1002/9781119099635

43. Osler W. Aequanimitas: with other adresses to medical students, nurses and practitioners of medicine.

Philadelphia: Blakiston, 1914.

44. Goodrich J, Cornwell J. Seeing the person in the patient: the point of care review paper. London: King's Fund, 2008.

45. Richards T, Coulter A, Wicks P. Time to deliver patient 
centred care. BMJ 2015;350:h530.

46. Jonas AD. Kurzpsychotherapie in der Allgemeinmedizin: Das gezielte Interview. 3rd ed. Würzburg: Huttenscher Verl. 507, 2009. (Jonas-Edition). Available online: http:// d-nb.info/995576459/04

Cite this article as: Röhrich C, Giordano J, Kohls NB. Narrative view of the role of health promotion and salutogenesis in the treatment of chronic disease: viability and value for the care of cardiovascular conditions. Cardiovasc Diagn Ther 2021;11(2):591-601. doi: 10.21037/cdt-20-610
47. Deutsche Gesellschaft für Kardiologie - Herz- und Kreislaufforschung \& Deutsche Hochdruckliga. Leitlinien für das Management der arteriellen Hypertonie. 1. Aufl. Grünwald, Kr München: Börm Bruckmeier, 2014. 